Canadian University Music Review

Revue de musique des universités canadiennes

\title{
The String Quartets of Barbara Pentland
}

\section{Gail Dixon}

Volume 11, numéro 2, 1991

URI : https://id.erudit.org/iderudit/1014109ar

DOI : https://doi.org/10.7202/1014109ar

Aller au sommaire du numéro

Éditeur(s)

Canadian University Music Society / Société de musique des universités

canadiennes

ISSN

0710-0353 (imprimé)

2291-2436 (numérique)

Découvrir la revue

Citer cet article

Dixon, G. (1991). The String Quartets of Barbara Pentland. Canadian University Music Review / Revue de musique des universités canadiennes, 11(2), 94-121.

https://doi.org/10.7202/1014109ar

(c) Canadian University Music Society / Société de musique des universités canadiennes, 1991
Ce document est protégé par la loi sur le droit d'auteur. L'utilisation des services d'Érudit (y compris la reproduction) est assujettie à sa politique d'utilisation que vous pouvez consulter en ligne.

https://apropos.erudit.org/fr/usagers/politique-dutilisation/ 


\title{
THE STRING QUARTETS OF BARBARA PENTLAND
}

\author{
Gail Dixon
}

Barbara Pentland is acknowledged to be one of the most important Canadian composers of this century. The principal source of information about her life and works, the book co-authored by Sheila Eastman and Timothy McGee entitled Barbara Pentland, ${ }^{1}$ was explicitly intended as a general overview. The representative works singled out for discussion were not subjected to detailed analysis, and, as stated in the book's preface, there are no sources for additional detail concerning the compositions. This article begins to address that void by providing a detailed look at specific aspects of some of her works.

The works which I have chosen to examine do not, in themselves, constitute a comprehensive representation of Pentland's stylistic development. However, because they are all in the same genre and are spread out across her output, they do serve as useful snapshots of various waypoints on her evolutionary path. Her string quartets span a period of about forty years and, with a new string quartet appearing approximately once in each decade, collectively they constitute as effective a medium as any in which to examine and illustrate specific aspects of her compositional methods.

Before embarking on a discussion of the quartets themselves, however, I shall provide a capsule summary of major influences and developments in Pentland's career. ${ }^{2}$ I shall then turn to the quartets, and, indeed, very specific aspects of those quartets, since it is obviously beyond the scope of this article to provide a comprehensive analysis of any one of them. Rather, I shall examine in considerable detail a limited number of excerpts drawn from the quartets in order to uncover some of the complexities of Pentland's craft.

Barbara Pentland was born in Winnipeg in 1912. Despite considerable parental opposition, she embarked upon formal compositional studies, first in Paris, then

\footnotetext{
${ }^{1}$ Eastman, Sheila and McGee, Timothy, Barbara Pentland. Canadian Composers Series 3. Toronto: University of Toronto Press, 1983.

2 I am indebted to Sheila Eastman and Timothy McGee, from whose pioneering study most of this information will be drawn.
} 
in New York, and later at Tanglewood with Copland and Hindemith. Her style, as it crystallized following the completion of formal studies in 1941-1942, could be broadly described as neoclassic. It was during the period from 1941 to 1948 that Pentland established herself in Toronto as one of Canada's musical pioneers, amid such colleagues as Ridout, Weinzweig, Somers and Adaskin. Toward the end of this period, she met Dika Newlin, who was then working on her translation of Leibowitz's Schoenberg et son école. Her conversations with Newlin undoubtedly did much to help Pentland look beyond what she described as the "over-emotionalism" of Schoenberg's music and to understand the potential relevance of his serial technique for her own work. During the years 1948-1955, Pentland was preoccupied with incorporating the elements of serial technique into her own well-developed neoclassicism. However, it was not until the late 1950 's that a significant shift was evident in her style. This came about not as a result of the adoption of serial techniques, but rather as a result of a visit to Darmstadt in the summer of 1955 . Compositions which she heard there, notably those of Boulez and Webern, had a profound impact which manifested itself almost immediately in her music. Over the past two decades her style has continued to develop, though the incremental changes have been modest by comparison with the quantum leap triggered by that visit to Darmstadt.

The magnitude of the changes which have taken place in Pentland's style from 1940 to the present is evident to even the most casual listener. However, certain elements of her style have remained remarkably constant. From a very early stage in her development she has created for each musical work (or major segment thereof) an "initial impulse" which gives rise to subsequent events, and she has relied upon such traditional techniques as fragmentation, rearrangement and recombination to develop her initial impulse in a coherent manner. Her frequent use of various kinds of symmetrical or circular structures further adds to the lucidity of her works. Her lifelong distaste for the emotional excess which she detects in the music of some of her contemporaries has undoubtedly contributed to her penchant for clarity, simplicity and logic in her own. Yet for all her interest in logical organization, she has never allowed any preconceived plan or method to override her musical intuition. As she wrote to me in a letter dated July 11 th, 1987 :

I recall in the '50s how European composers (Boulez in "Structures" for instance) were creating a schema where all pitches and durations were worked out before a note was written! As an intuitive composer this would have stopped me "dead in my tracks": the musical impulse (motif or whatever) comes first.

The foregoing very brief survey must suffice as an introduction to the main focus 
of this article: a discussion of selected aspects of Pentland's string quartets. I shall provide contextual information and a broad general outline for each work, followed by a detailed discussion of selected excerpts.

Pentland's String Quartet no. 1 was written in 1944-45, squarely in the middle of the seven-year style period defined by Eastman/McGee as "Early Mature." This style could be broadly defined as neoclassic, and was characterized by a conscious reliance on models and techniques of the past to provide both largeand small-scale organization. For example, she often used real melodic themes (initially quite lengthy, though later in the period somewhat shorter) which were then typically fragmented and the fragments manipulated. She favoured traditional formal models, like sonata form, and often sought to unify all the movements of a work through various formal and motivic means. Her largely contrapuntal textures, conventional rhythmic groupings and regularity of pacing attest to her allegiance to the teachings of some of her mentors (e.g., Hindemith, Copland). Her works of this period assert the hegemony of one or more focal pitches, sometimes with ancillary functional associations.

Pentland's String Quartet no. 1 exemplifies all of the above characteristics, with a number of interesting nuances of its own. The three movements appear in the usual fast-slow-fast ordering, and each adheres to a traditional formal structure, at least in broad outline. For example, the model for the first movement is clearly sonata form. The exposition has two theme areas, each supplied with its own focal pitch. There is a developmental middle section followed by a modified restatement of the opening and a short coda. Example 1 reproduces the opening twelve measures of this first movement, and will serve as an illustration of her style.

Example 2a shows the focal pitches at the beginning and end of each of the three movements in this quartet. Support is frequently provided to focal pitches by major or minor triads, as example $2 b$ (the last chord of movement one and the opening of movement three) illustrates. Indeed, at this stage in her stylistic development, Pentland still retains the occasional remnant of traditional functional tonality. The overlapped plagal cadence on $\mathrm{A}$ at $\mathrm{m} .10$ in the first movement is one instance (refer to example 1). Another is found at the end of this movement, where directed tonal motion lends authority to the reestablishment of $\mathrm{C}$ as tonal centre (see example $2 \mathrm{c}$ ). ${ }^{3}$

Eastman/McGee state that by the time of the first string quartet Pentland had "refined a technique of unification through the use of a single basic interval that

3 The pitches shown in the example have been projected into prominence by virtue of their long duration and registral placement. 

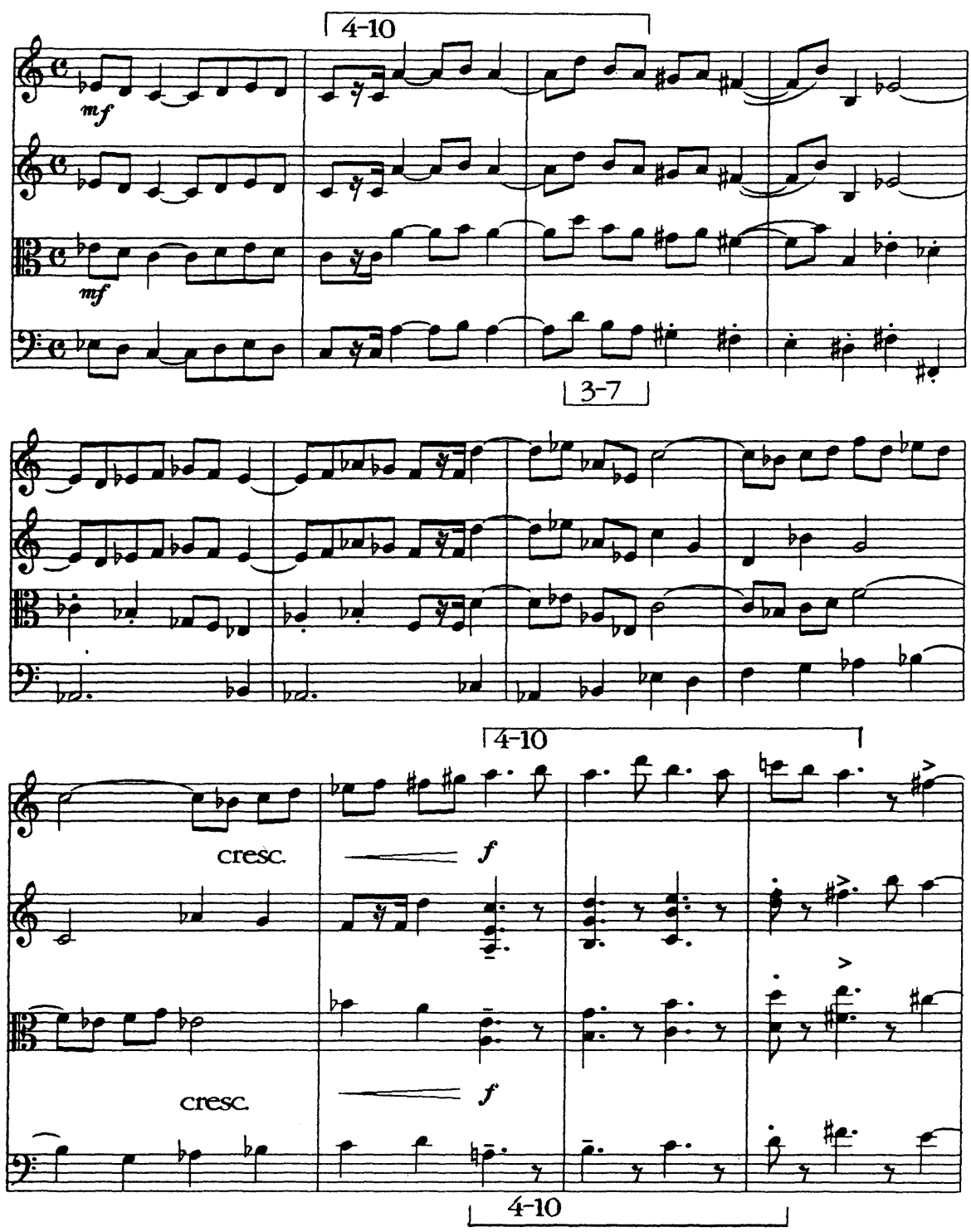

Example 1: String Quartet no. 1, mm. 1-12. 
movement

1
2
3

Example 2a: focal pitches

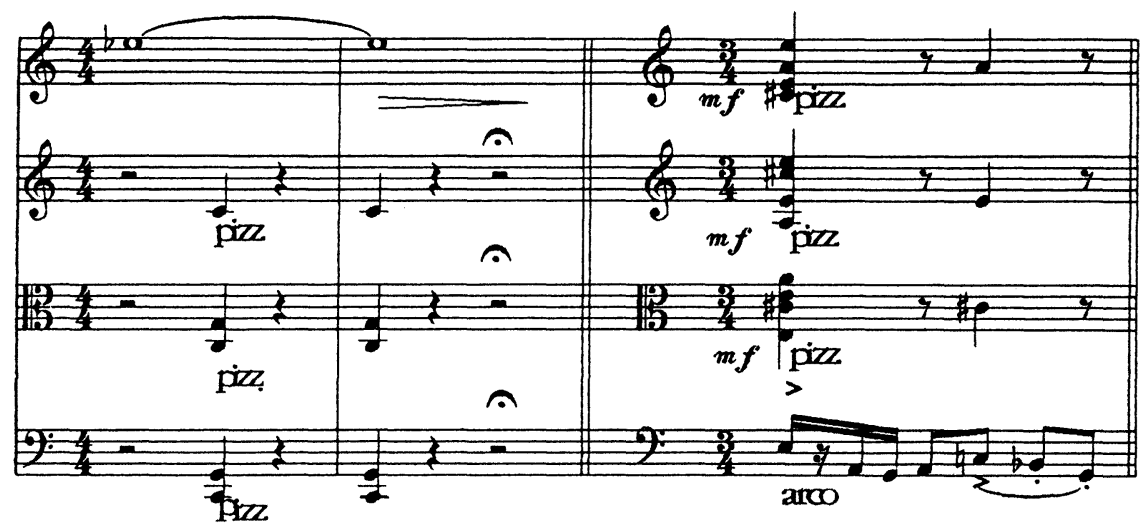

Example 2b: String Quartet no. 1, end of movement 1, opening of movement 3.

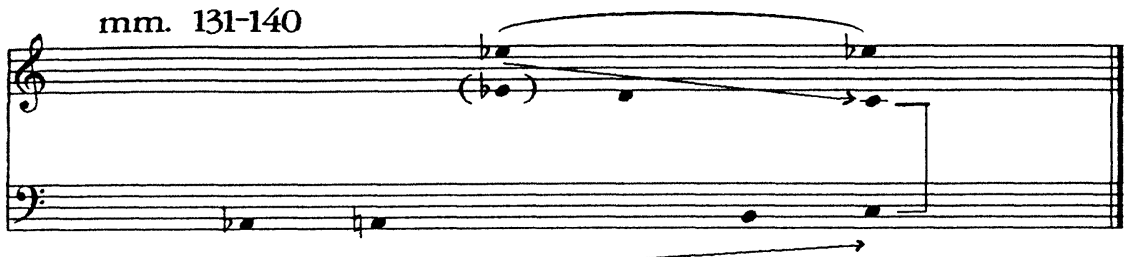

Example 2c: String Quartet no. 1, end of movement 1. 
is given different motivic shapes." ${ }^{4}$ While it is perfectly true that a single basic interval does commonly permeate a given work or segment thereof, I believe that, in the case of the first string quartet at least, Pentland has gone further: she has experimented here with a basic interval complex - an unordered pc set - as a referential source and means of obtaining coherence. Both small-scale and large-scale structures are guided by the pitch-class set $3-7[0,2,5]^{5}$. On a small scale, the clearest presentation of the set is at the opening of the second movement, carefully demarcated by a slur. The addition of the fourth note, B, to the initial $\mathrm{D}, \mathrm{C}, \mathrm{A}$ produces the superset $4-10[0,2,3,5]^{6}$ (see example $3 \mathrm{a}$ ). The thematic material which opens the second section of the movement (beginning at m. 39) presents the same pitches, now reordered, though maintained in the same register (example 3b). Pc sets 3-7 and 4-10 appear as important elements within the opening theme of the third movement as well (example 3c). Pentland ensures the prominence of this material in its initial statement by accentuation and articulation, and further enhances its prominence at crucial points later in the movement by isolating it from the rest of the theme. One of many such instances is shown in example $3 \mathrm{~d}(\mathrm{~mm} .81-82$ of the 3rd movement) which illustrates the isolation of these opening sets to signal the recasting of the opening theme in triplets. The three participating instruments (violin 2, viola and cello) play the same line, but each begins on a different note; the resultant parallel major triads further reinforce the prominence of sets 3-7 and 4-10.

In the light of the foregoing, one understands retrospectively the significance of the opening of the first movement (refer again to example 1). In its first overt appearance at $\mathrm{m} .3$, pc set 3-7 is expressed in the tones D,B,A, in that order. In mm. 10-12, pc set 3-7 is expanded to the superset 4-10 in two different voices and in two different orderings: violin 1 first states pc set 3-7 (A,B,D), then explicitly expands the figure to $\mathrm{pc}$ set $4-10$ at $\mathrm{m} .12$ by inclusion of the tone $\mathrm{C}$.

4 EASTMAN/MCGEE, op. cit., p. 48. One wonders how one "basic interval" can be given "different motivic shapes." Presumably the authors mean that the basic interval serves as a source of embellishment by other intervals.

5 I refer here, and elsewhere, to Allen Forte's tabulation of unordered pc sets in his The Structure of Atonal Music (1973), pp. 179-181.

6 There is, of course, a strong connection between pc sets 4-10 and 3-7: pc set 4-10 [0,2,3,5] contains pc set 3-7 as two of its four trichordal subsets $[0,2,5]$ and $[0,3,5]$. Further, they are inversionally equivalent, so that any form of pc set 3-7 can be recognized as a subset of set 4-10, regardless of its disposition. The remaining trichordal subsets $([0,2,3]$ and $[2,3,5]=p c$ set $3-2)$ find considerable prominence in the work as well. The opening three measures of the second theme of the second movement (II:mm. 39-41, see example 3) provide one illustration. The opening and close of the first movement provide another (note the strongly incisive E-flat-D-C). 


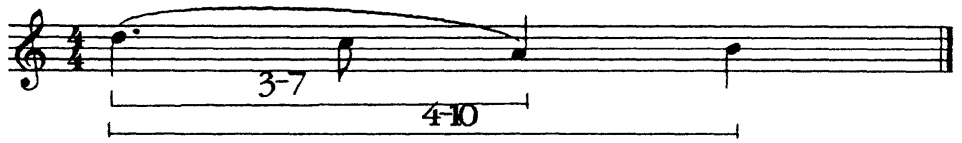

$3 b$

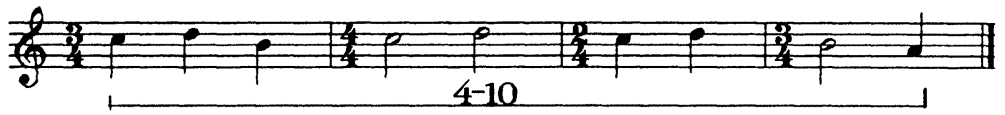

$3 c$

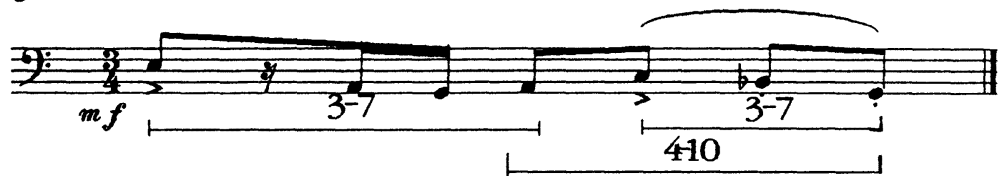

$3 d$

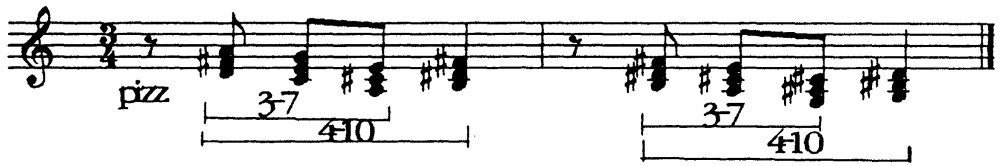

Example 3a-d: String Quartet no. 1, pc sets 3-7 and 4-10.

Prominent by virtue of register, dynamics and rhythm, the importance of these tones is unmistakable. Appearing simultaneously in the cello part are the same four tones, this time in a new ordering $(A, B, C, D)$. Once again, their prominence is assured because of register, dynamics and doubling. Looking back to $\mathrm{mm}$. 23 , we now observe those same four tones in yet another order: $C, A, B, D$. The $C$ and $D$ are prominent because they define the extremes of register within the first three measures of the piece, while the A gains importance because it is approached in a rhythmically incisive manner and by leap. The subordinate role of the B in this first appearance is reflected by its omission from the large-scale tonal organization of the piece. Indeed, we now see that the overall tonal plan, as shown in example 2a, has a more global significance than we had previously thought: focal pitches C, D and A comprise pc set 3-7, the very set (and indeed the very pitches) which have proved to be a generative source for much of the motivic material in the piece as well.

Clearly, pc set 3-7, with its superset 4-10, does not generate all, or even most of the small-scale organization of the piece. However, it is the one element that is common to all movements. Moreover, because of the many reorderings of these sets, it is clear that Pentland does not view them simply as motives, but rather as generative intervallic complexes - unordered pc sets. An understanding of this 
concept will prove to be an essential tool in unlocking some of the secrets of Pentland's serial techniques.

In 1948 Pentland entered what Eastman/McGee label her "Transition period" (1948-1955). It was during this period that she began to experiment with elements of serial technique. ${ }^{7}$ The second String Quartet, completed in 1953, is Pentland's first real serial work. ${ }^{8}$ Its composition apparently gave Pentland a considerable amount of trouble, since it took her nearly a year to complete. In this quartet, as in other works of this transitional period, she was struggling to find her own unique solution to the problem of amalgamating serial techniques with a neoclassic style. Although one might have anticipated a substantial stylistic shift as a result of the new method of generating her material, in fact the changes, from the listener's point of view, were surprisingly slight, for reasons which will become apparent as we proceed.

The second quartet consists of five discrete movements, each of entirely different musical character. Pentland's well-known penchant for incorporating mirror techniques into her formal plans is evident in this quartet; not only does the first movement end with a retrograde of its opening bars, but this same material is mirrored at the beginning and end of the fifth movement as well, creating a form with easily audible circularity. All five movements are integrated at the most fundamental level by their relationship to a common tone row, though this fact is by no means obvious, at least with respect to the middle three movements. Eastman/McGee postulate that the departures from the row which are apparent in these middle movements can be accounted for by the existence of a variable final tetrachord in the row. ${ }^{9}$ George Proctor asserts that the work coheres because all movements emanate from the first five notes of the opening 12-tone row. ${ }^{10}$ I would like to suggest an alternative interpretation - one that similarly stems from Pentland's well-known practice of basing an entire composition on its opening material. Example 4 shows that opening material, with the order numbers ${ }^{11}$ of the two concurrent (though temporally displaced) prime forms.

7 Up until this time Pentland had identified serial technique with what she viewed as the overly emotional approach of Schoenberg, and had therefore avoided adopting the technique herself. However, when she saw that some of her colleagues (e.g., John Weinzweig) had been successful in using the technique without such emotionalism, she decided to try it for herself.

8 Although she began experimenting in a tentative way with serial techniques in 1948, her second string quartet was her first serious effort to use serialism on a large scale.

9 Eastman/McGee, p. $65 f$.

10 Proctor, George, Canadian Music of the Twentieth Century, p. 83.

11 The convention used for ordering tones of the row is that in which the first tone is numbered " 1 " and the last "12." Order numbers for the inverted form of the row (beginning at $\mathrm{m}$. 8) are enclosed in parentheses, while those for the two unfoldings of the prime form are not. Order numbers 11, 10 and $8(\mathrm{~mm} .3-4)$ are underlined because their premature appearance is significant, as we shall see later. 


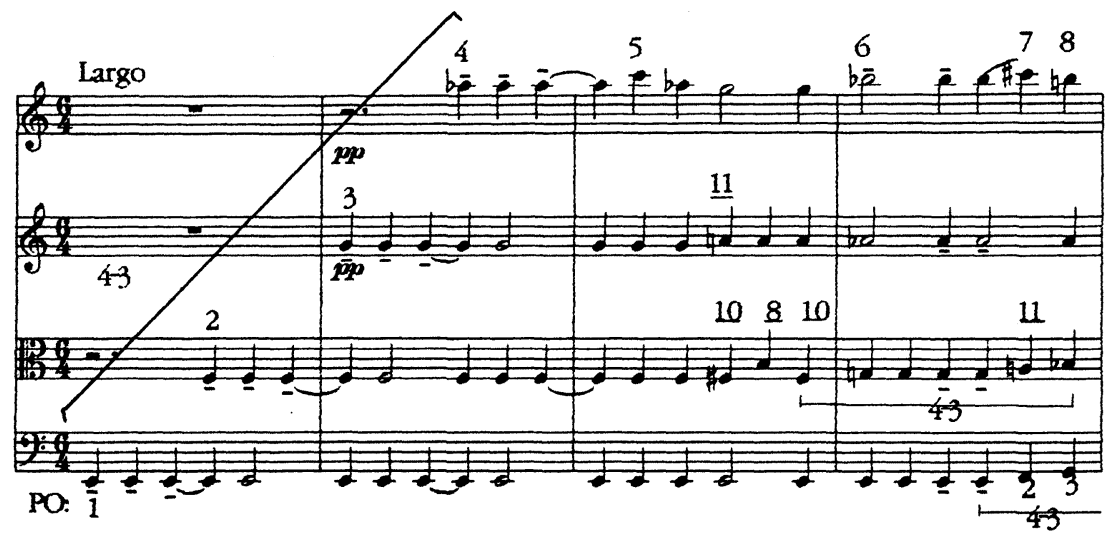

43
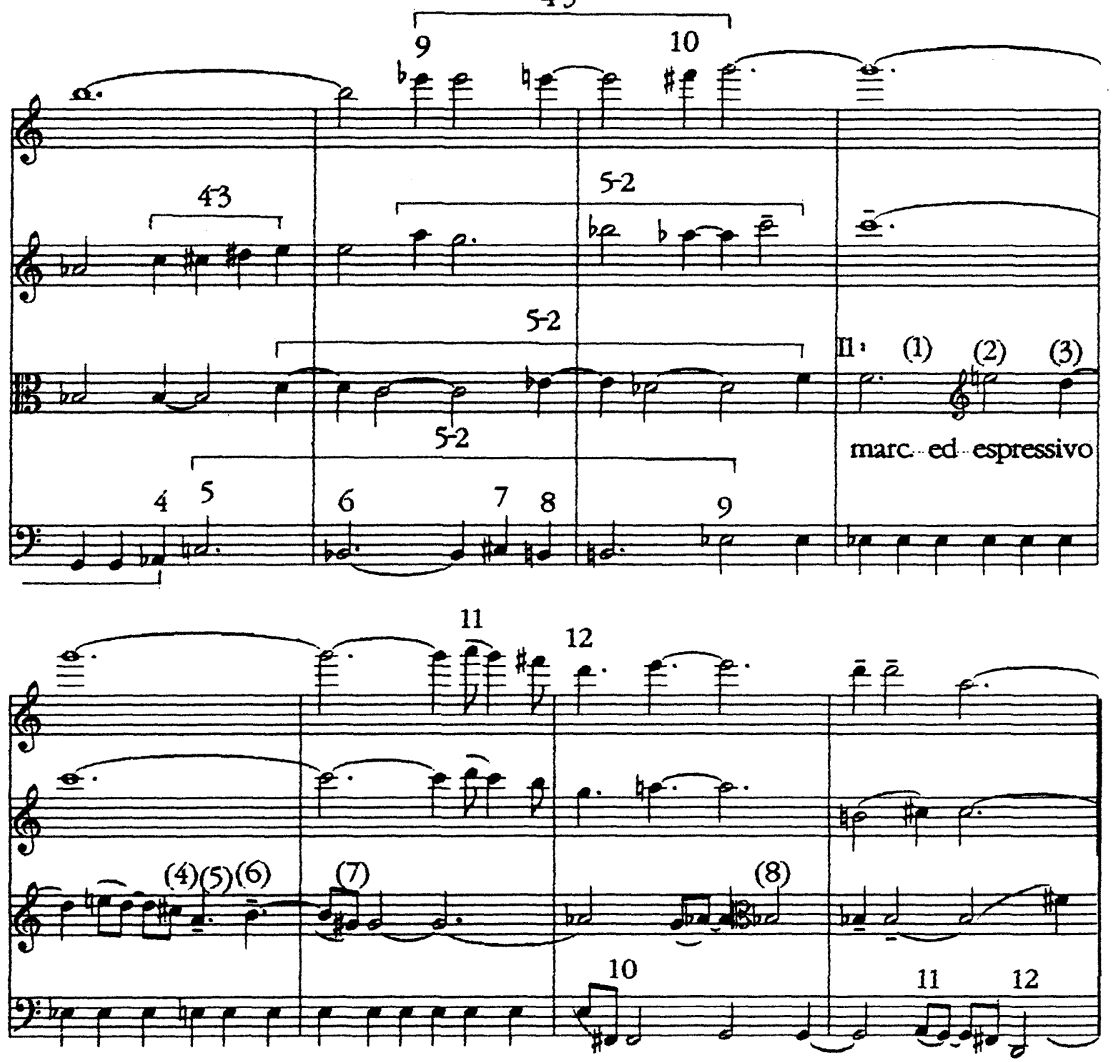

Example 4: String Quartet no. 2, mm. 1-12. 
The first hint of Pentland's rather cavalier treatment of row ordering appears as early as $\mathrm{m}$. 3, where the pitches F-sharp, B and A occur prematurely. ${ }^{12}$

The opening tetrachord (pc set 4-3, $[0,1,3,4]$ ) is of such importance in this work that it amounts almost to a motto. Note the cumulative entry of these tones, a process which draws attention to this opening tetrachord, both melodically and harmonically. This motto is routinely isolated from the rest of the row for independent statement. However, it does not always occur in the texture as order numbers 1-4; Pentland uses a variety of means to ensure its appearance in other contexts as well. Note the interruption of the row statement by the insertion of previously heard tones in order to produce the transposed motto in the first violin at mm. 6-7 (order numbers 9-1-10-3). Both the second violin and the viola feature further transposed statements of the motto as well (order numbers 5-79-1, 2nd violin, m. 5, and order numbers 10-3-11-6, viola, mm. 3-4, as shown in example 4). The point here is that Pentland deliberately and consistently manipulates her row in order to produce certain characteristic linear adjacencies. I believe that the apparently entirely unrelated opening of movement 3 is derived from the movement 1 material in just such a manner.

Movement 3 opens with a 12-note "theme" which recurs frequently as a kind of ritornello throughout the movement. The fact that in almost all its appearances the theme is accompanied by a different set of notes in the other parts argues for treating it as a secondary referential ordering for this movement. A comparison of this ordering with that of the original row quickly dispels any notion that the differences result merely from some change in the final tetrachord. Even the opening "motto" tetrachord is unavailable among adjacent tones of this new theme, though the fact that the motto does appear prominently throughout the movement lends credence to the notion that the original row does indeed serve

12 One can only conjecture about Pentland's intention in introducing these pitches prematurely, and at such an early stage in the piece. Perhaps she wished to reinforce the first purely melodic gesture of the piece (the first violin's A-flat, C, A-flat) by immediately imitating its contour (in the viola's F-sharp, B, F-sharp). We shall see later how Pentland makes use of these anomalous pitches. The premature statement of the A-natural in the second violin might perhaps be explained as a desire on Pentland's part to avoid octave doubling, which would have resulted had she retained the G. It should be noted that Pentland has never allowed herself to be strait-jacketed by the serial technique, and that unorthodoxies of this kind abound in her work. As she wrote to me in a letter of July 11 th 1987:

...where the serial technique is part of the structure, the motif is still the demanding force. I am not a "true" serialist; it is a governing principle only.

Indeed, this early exploration with serial technique provides clear evidence of her willingness to suspend logical method in favour of intuition, should circumstances warrant. 


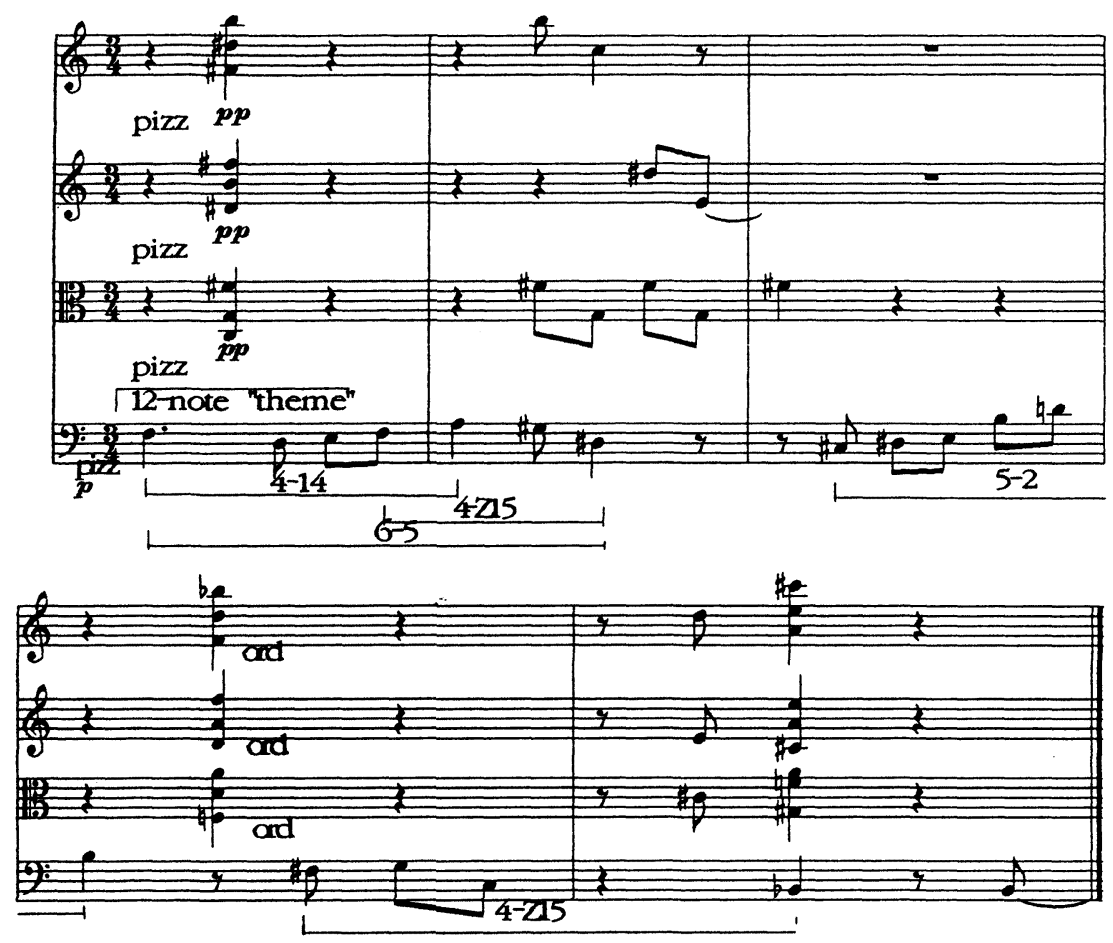

Example 5a: String Quartet no. 2, movement 3, mm. 1-5.

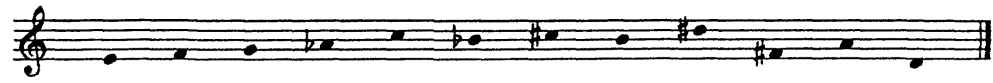

Example 5b: String Quartet no. 2, row.

as the basis of the movement. Example 5a reproduces the 12-note "theme" of the third movement, while example 5 b shows the tone row which is the basis for the entire work. In example $5 \mathrm{a}$, note that the accompanying chords reinforce the theme in mirror fashion (i.e., the chords in the first half of the example focus on salient intervals from the second half of the theme, and vice versa).

How does one account for this distortion of the original row in the opening theme of this third movement? The clue, as before, lies in the opening material of this quartet. Movement 3 begins with the tones F,D,E,F,A (pc set 4-14, [0,2,3,7]) (refer to example 5a). This set first achieves motivic significance in the work as 
a whole when it appears as order numbers 2-3-4-5 (I1) in mm. 8-9 in the viola. Attention is drawn to the set at that point by the eloquent leap to the $\mathrm{E}$ in $\mathrm{m}$. 8, and by the use of eighth notes - the first in the work-in m. 9. Of particular motivic significance is the segment indicated by the solid line in example $6 \mathrm{a}$.

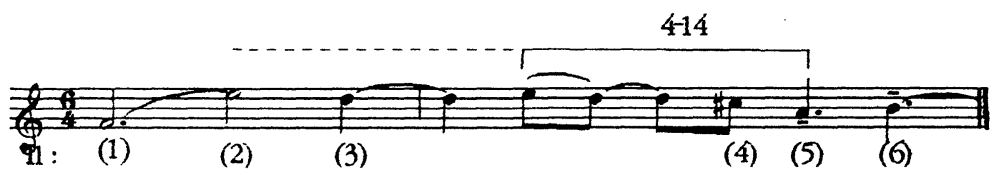

marc edespressivo

Example 6a: String Quartet no. 2, movement 1, viola, mm. 8-9.

This motivic segment is repeated prominently many times in the first movement, as order numbers $2-3-4-5$, before appearing in prime form as an expanded interpolation between order numbers 5 and 6 in a revised version of opening material, now at P8 (cf. mm. 3-4 and 36-38). Example 6b illustrates:

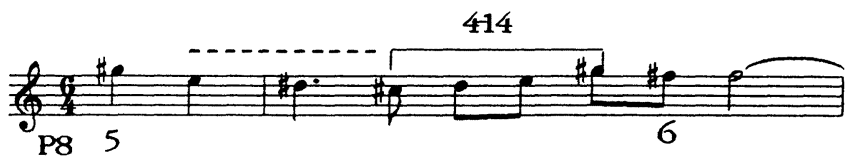

Example 6b: String Quartet no. 2, movement 1, violin, mm. 36-37.

Its importance as a motive in this first movement is unequivocal. In its statement as the opening of movement 3, this pc set 4-14 (F,D,E,F,A, the nucleus of the opening gesture) acquires an appendage - the dyad G\#-D\# - producing the larger set $6-5[0,1,2,3,6,7]$ (refer once again to example 5a). A look at the opening of the first movement (see example 4) will reveal the origin of this dyad: Order numbers 2-3-4-5 (F-G-A-flat-C) PLUS the anomalous tones B and F\# in the viola together yield pc set $6-5$, which, transposed at $t=9$, constitutes the first gesture of the third movement.

The second gesture of the third movement theme (pc set $5-2,[0,1,2,3,5]$, example 5a) is a permutation of order numbers 5-6-7-8-9 of the original row. These order numbers were accorded special significance on their initial presentation in the cello (in movement 1 ) by being immediately imitated, first by the viola, then by the second violin (refer to example 4, mm. 5-7). The third gesture of the third movement theme is, quite simply, what is left over from the first two in order to complete the entire chromatic. (One wonders if Pentland was 
aware that the set formed by this third gesture $(4-\mathrm{Z} 15,[0,1,4,6])$ is the same as that formed by the last four notes of the first gesture.)

Similar derivations from the opening movement can be shown for the other basic material in this quartet. For example, the derivation of the material for the second movement bears a remarkable similarity to the process we have just seen (compare examples 7 and 4). The first two measures of the 2 nd movement ${ }^{13}$ are derived from the opening of the first movement; they consist of a permutation of order nos. 1-4, this time with the addition of the anomalous $A$ from the 2 nd violin part, $\mathrm{m} .3$ (= pc set $5-3[0,1,2,4,5])$. The five new pitches which follow in measures 9-10 are also derived from the first movement: they consist of a permutation of order nos. 5-9 (pc set 5-2 [0,1,2,3,5]). The two new pitches in mm. 12-13 complete the total chromatic.

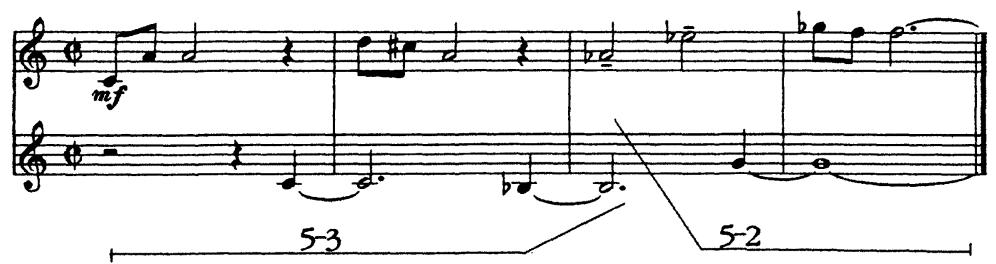

Example 7: String Quartet no. 2, movement 2, mm. 7-10.

Having evolved a subsidiary ordering in the manner described above, Pentland then isolates certain segments for independent development. Three 4-note segments are individually subjected to the usual row manipulations of inversion, retrograde and retrograde inversion. They are fragmented into their intervallic components, interlocked, and the resultant new interval complexes in turn extracted and projected independently. In several instances a new interval complex emerges not from interlock but quite spontaneously, as a result of expansion of the original shape of one of the segments.

Pentland's basic principle - that of isolating an interval complex for independent use - has already been seen in Quartet no. 1. Her flexibility in the application of serial procedures is such that she has been able to carry forward the same principle in this quartet as well. Her particular version of serialism at this stage is rooted in a very fundamental way in traditional developmental techniques, i.e., the fragmentation and recombination of elements, coupled with the evolution of

${ }^{13}$ The second movement actually begins at $\mathrm{m} .7$, following six measures of monophonic introduction. 
new forms of those elements through interlock and alteration of interval size. Despite the slight increase in dissonance which is evident with Pentland's adoption of serialism, the retention, almost unchanged, of her original composition techniques yields a net result which differs surprisingly little from her earlier, non-serial works.

The last three string quartets were written during Pentland's mature style period: 1955 to the present. ${ }^{14}$ As stated earlier, a visit to Darmstadt in 1955 was the catalyst for a substantial shift in Pentland's style. The string Quartet no. 3, composed in 1969, is entirely representative of this new style, a style which is both apparently and demonstrably different from that of her second quartet. A short example from the opening of the third quartet will suffice to illustrate the magnitude of the change. ${ }^{15}$ (See example 8.)

The motives are shorter, and more jagged in contour. Gone are the long lyrical gestures and busy scale passages of the earlier quartets. There is a new economy in her "initial impulse," both in its first statement and in its subsequent working out. Gone, too, is the comfortable familiarity of an easily perceptible metrical context; this work is frequently non-pulsatile and full of nervous energy. The listener is required to focus on small rhythmic/melodic units and the myriad of ways in which they interrelate. However, some important elements of her earlier works remain. In her approach to form, for example, Pentland remains entirely traditional, with individual movements conforming to classical models. Also, as in her earlier works, one of her primary goals is to create a cohesive effect. In Quartet no. 3 she achieves this goal in a way now familiar to us-by drawing upon her opening material as the generative source for all subsequent events. Further, each movement grows out of the previous one, and the last movement relates to the first, creating an explicitly circular structure. Mirror techniques remain in evidence, not only on the horizontal plane (many of the movements embody formal palindromes), but now on the vertical plane as well. For example, the work opens with a double inverted canon (as illustrated in example 8), exact as to pitch, though not as to duration. The row forms used are PO (beginning with the viola) and I1 (beginning with the first violin). This pairing of combinatorial

14 Eastman/McGee call the period from 1955 to the present the "Second Style," and in fact they discern within this period one very short segment (1955-58), which they call Second Style I, and one very long segment (1958 to the present) which they call Second Style II. Since they make it clear that the changes in style which distinguish the two segments are not dramatic (see p. 83), but rather evolutionary, and since, in any case, the remaining string quartets all fall within the Second Style II, I shall not belabour the distinction.

${ }^{15}$ A rather unkind review in the Victoria Daily Columnist (February 20, 1971) compared Pentland's String Quartet no. 3 to the sound track for a headache remedy! 

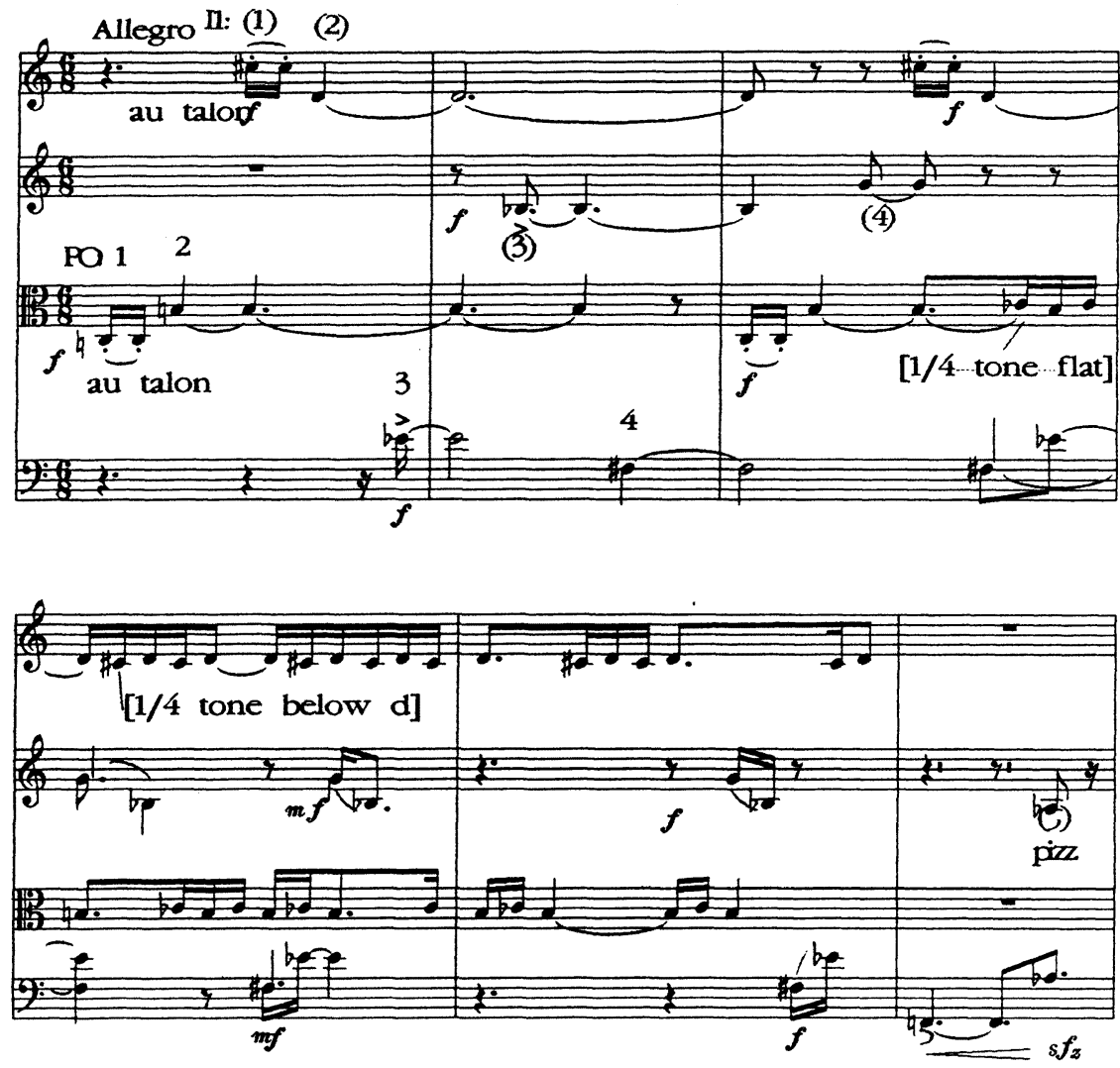

Example 8: String Quartet no. 3, mm. 1-6.

row forms at the outset is surely not accidental, since she exploits this feature throughout the work. In this and other ways, her application of serial techniques shows increased sophistication, though many of her basic premises remain. Rigid adherence to serial ordering had certainly not been a feature of Pentland's compositional technique in her earlier serial works, and exposure to the music of Webern did little to change this. As before, she tends to be more strict with respect to ordering at the beginning of a section than at the end. By the end of a section, the serial ordering is often obscured by such means as retention or reiteration of pitches so as to bring originally non-adjacent pitches into relationship withone another. The method which we saw in Quartet no. 2- the extraction of segments of the row for subsequent independent development - is still in 
evidence in this quartet. With Quartet no. 3, we see yet another method of deriving characteristic figures: Pentland creates motives from tones which are fortuitously related by virtue of the simultaneous unfolding of two different row forms. The first seven measures of the Presto movement (example 9a shows the first four measures, example $9 \mathrm{c}$ the following three) provide a clear illustration of the way in which both adjacent and non-adjacent tones are extracted and projected as independent units. In fact, these measures provide a clarification of the essential motivic material of this last movement. At first glance, there appears to be absolutely no relationship between the opening four measures of this Presto movement (example 9a) and the original row of the first movement (example 9b). Although there are some tertian relationships amongst adjacencies in the row, there is no form of the row which could reasonably accommodate the material of the opening four measures of the Presto movement. An understanding of the source depends upon an examination of the three measures which immediately follow (example 9c), and in turn upon the knowledge that not one but two row forms are together generating the motives. A comparison between examples $9 a-9 c$ will clarify.
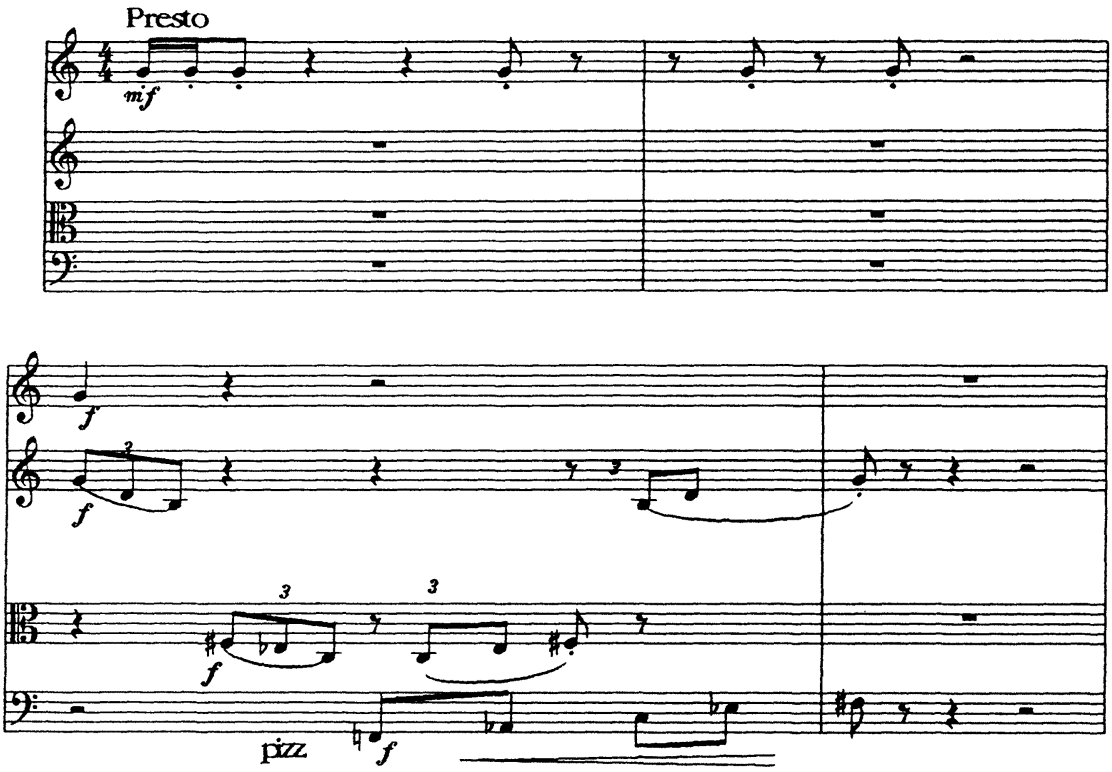

Example 9a: String Quartet no. 3, Presto movement 3, first 4 measures. 


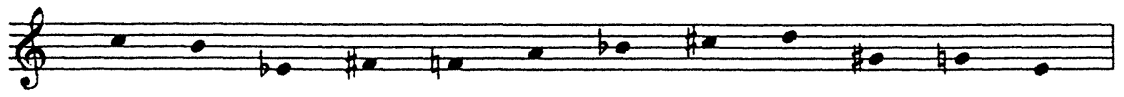

Example 9b: String Quartet no. 3, Presto row for movement 1.

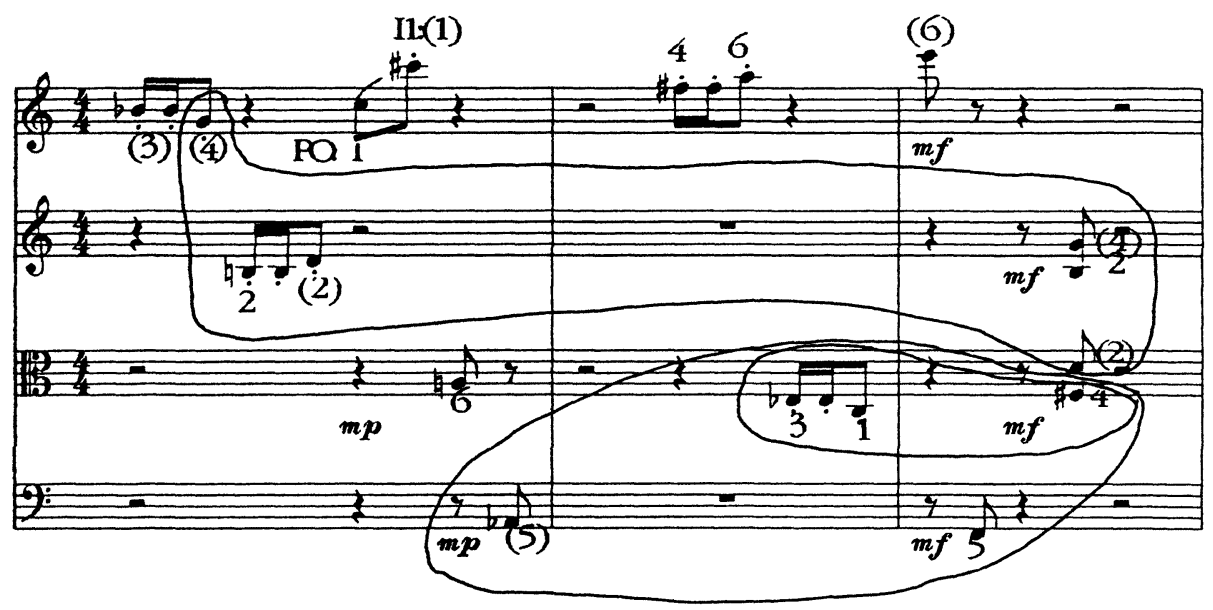

Example 9c: String Quartet no. 3, Presto movement 5th, 6th and 7th measures.

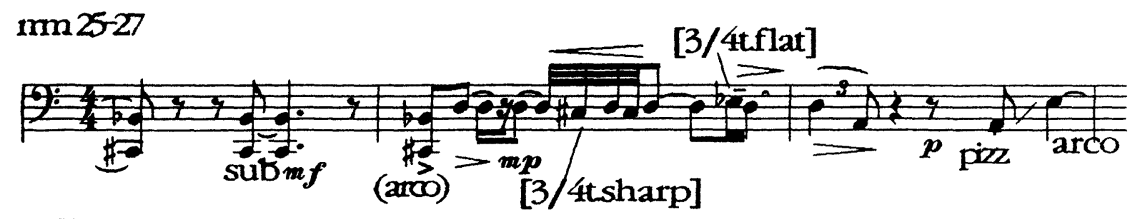

m32

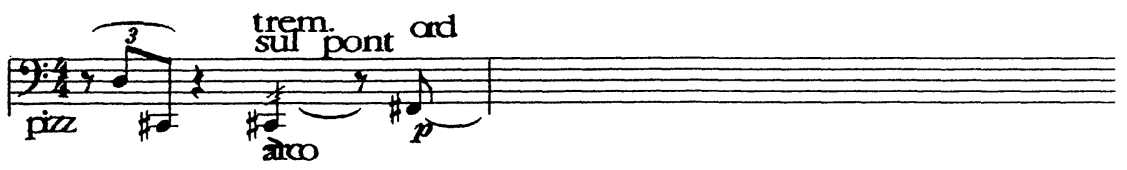

Example 10: String Quartet no. 3, end of movement 2.

With Quartet no. 3 we see Pentland turning to three new devices (new with respect to the earlier quartets, at least) which all have the same purpose: to enhance, clarify or reinterpret material which has already been presented. One such device occurs in the domain of colour. Pentland uses a host of colouristic effects ranging from pizzicato with the fingernail to variable width vibrato and 

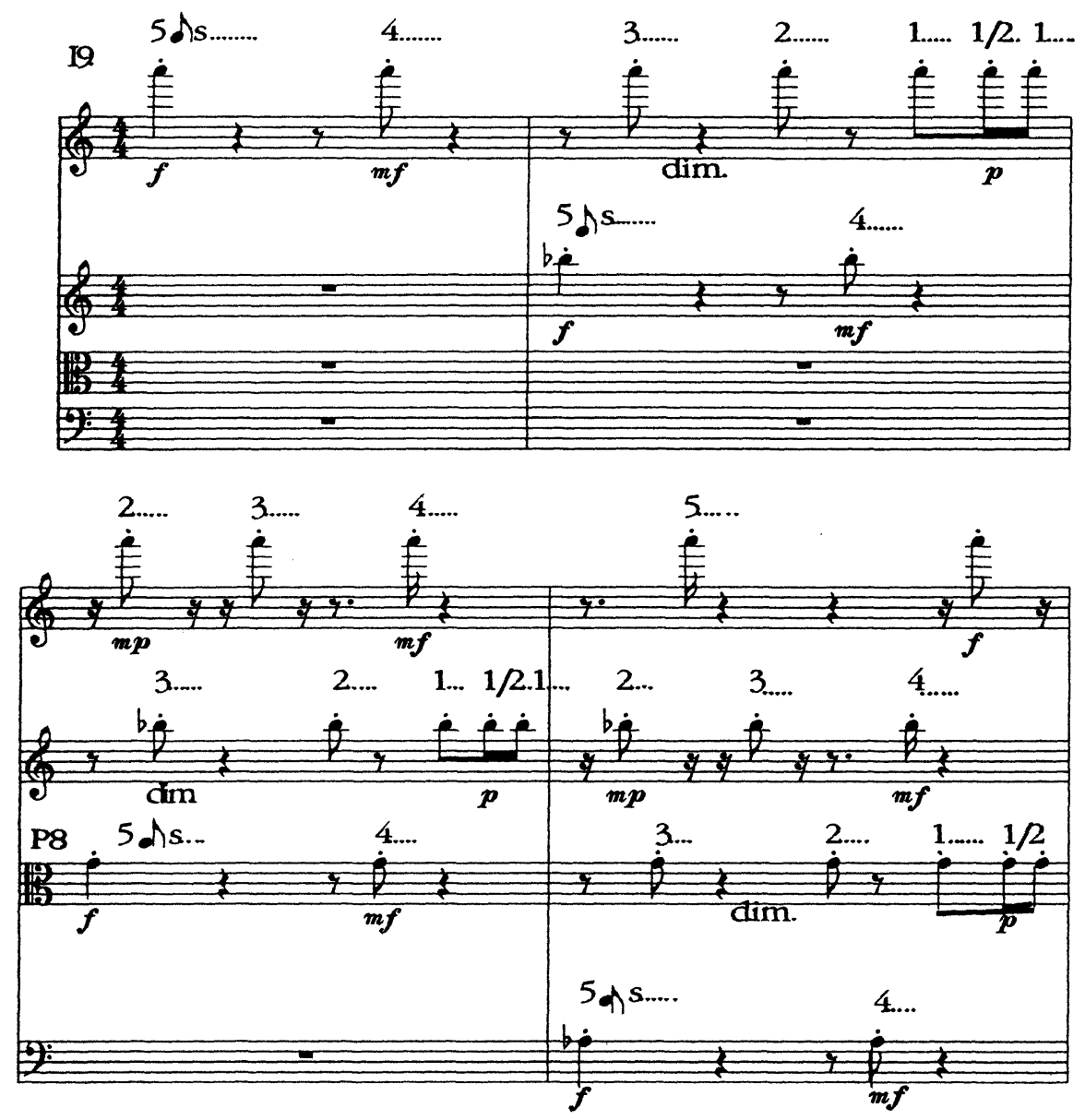

Example 11: String Quartet no. 3, movement 4, mm. 87-90.

other microtonal inflections. Example 10 (drawn from the second movement) shows a concentration, intensity and variety of such devices which is by no means unusual in the quartet.

Another such device can be seen in the realm of rhythm. We have already mentioned a perceived lack of regular pulse in this work, with a concomitant disassociation of individual musical events from a broader metrical context. Pentland provides a good example of this kind of disassociation in measure $87 \mathrm{ff}$ of the fourth movement. Example 11 shows the beginning of an extended 
unfolding of 19 in the upper two voices and of P8 in the lower two. The texture here consists of identical, but displaced, rhythmic palindromes (another example of Pentland's preoccupation with mirror techniques). The tones of the opening of the work have been disassociated from one another by placing each in its own layer and subjecting it to independent rhythmic manipulation. The opening material has thus received new definition by rhythmic means.

The displaced layering of the patterns in Example 11 creates an effect of randomness which is paralleled elsewhere in this quartet by the inclusion of aleatoric sections. This is another of the devices now used by Pentland to enhance, clarify or reinterpret her material. Pentland has never been comfortable with the idea of delegating any substantial degree of control of the compositional process to her performers. An examination of the four "aleatory zones" in this quartet will quickly dispel any notion that she has done so, to any large degree. First, Pentland ensures that her own personal view of her material has been firmly entrenched in the listener's mind by placing the aleatory zones late in the movement, after her material has been firmly established and subsequently developed by more traditional means. Second, the pitch material which she permits in the aleatory zones is rigidly restricted. The material relates to pitches which have been heard immediately before, or anticipates those which are to be featured in the upcoming section; alternatively, it consists of a statement of a row segment. Pitches must be played only in the order indicated (shown by a single arrow), or they must be played first in the order indicated, then in any order selected by the performer (as shown by a single arrow followed by a wavy line). In short, in these aleatory zones Pentland requires her performers to encapsulate that blurring of the distinction between ordered and unordered pitches which has been implicit in her compositional technique for a very long time. In the hands of sensitive players, these improvised sections merge smoothly with the composed sections of the work, and are perceived as controlled enhancement and reinterpretation rather than virtuosic free flight.

The stylistic changes which are heard in the Quartet no. 4 are, in the main, more evolutionary than revolutionary. The features which were so strikingly new in Quartet no. 3 are all present in this fourth quartet as well; indeed, these elements now assume an even greater importance and are handled by Pentland with increased assurance and skill.

This quartet, written in 1980 , is unified by the now-familiar device of restating the opening material in retrograde at the end of the work. There is a single long movement, divided into four overlapped sections. This is a logical step for Pentland to have taken, following her attempt, in the third quartet, to obliterate the seams between movements by evolving each movement from the material of 


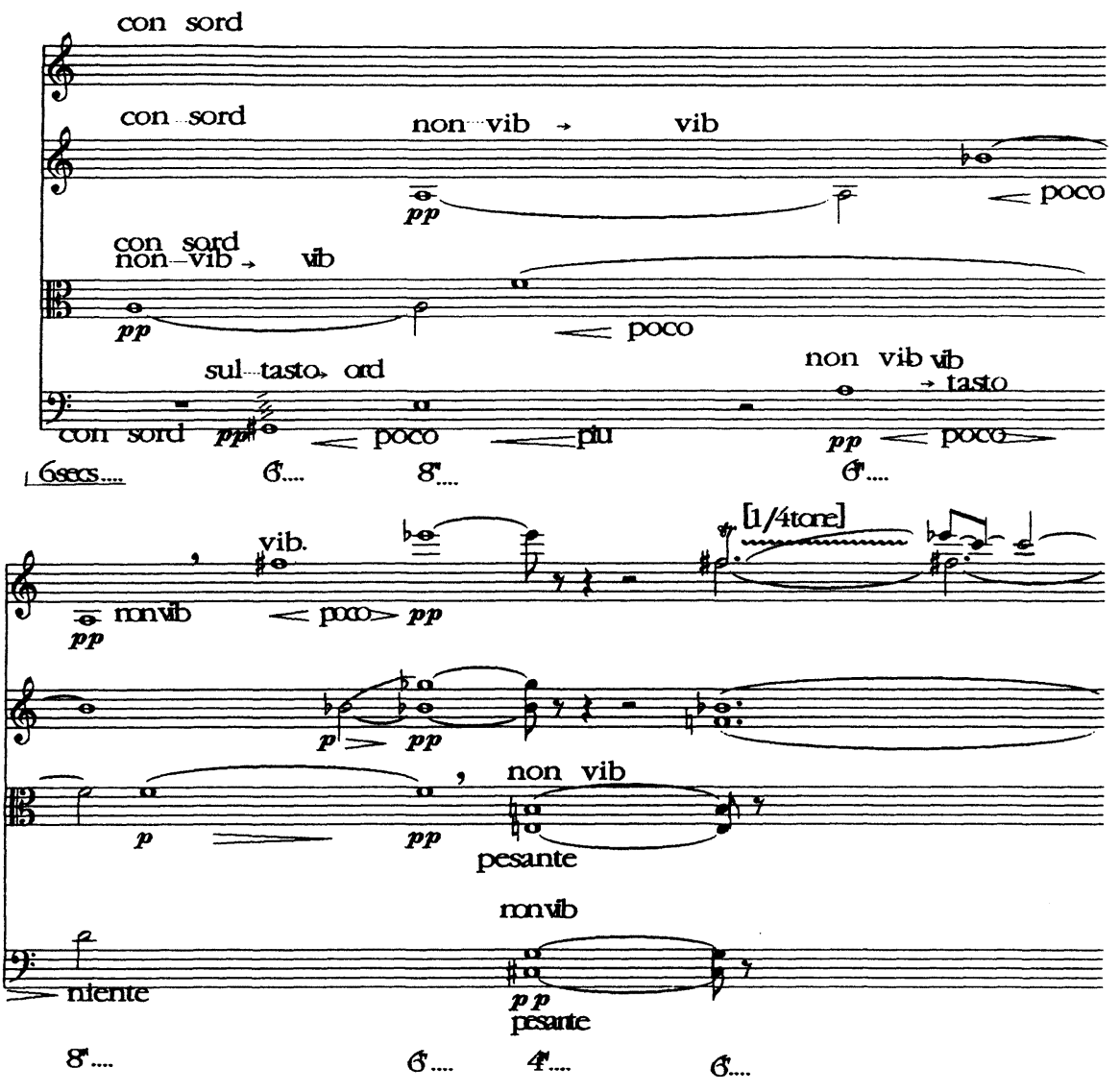

Example 12: String Quartet no. 4, opening.

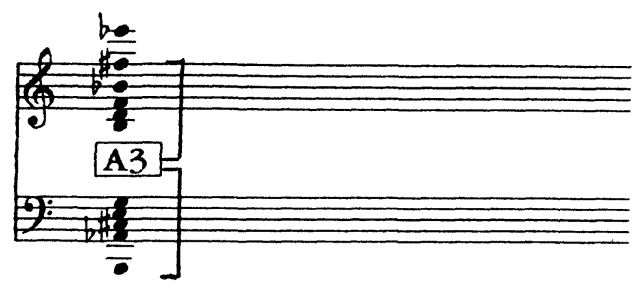

Example 13: String Quartet no. 4, opening measures. $\mathrm{A}^{3}$ as axis of symmetry. 
the previous one. The cohesiveness of the fourth quartet is further enhanced by a recurrent focus on the pitch class $\mathrm{A}$ - the first element of the row. This A occurs prominently at least nine times during the work, given subtle shading by appearing in various registers and instruments and with an assortment of dynamic levels, colourings and articulations.

The quartet begins with $\mathrm{A} 3$, which is passed through all four instruments. It is distinguished by an initial non-vibrato attack which, in the first three iterations, evolves to a vibrato as the pitch is sustained. In the last iteration, the vibrato is deferred until the note following the A3. The opening of the quartet is shown in example 12.

The pitch A3 is singled out in yet another way: it forms the centre of a symmetrical pitch arrangement (successive ics 2,3,3,5,8 above and below). ${ }^{16}$ Since this section exposes the 12 - tone series, a complete symmetry about a central pitch is, of course, impossible. ${ }^{17}$ The unpaired pitch is the highest of the collection-E-flat. Example 13 is a compilation of the opening measures of the quartet (to the first beat of measure 19).

The reaction of many listeners on hearing this quartet is that it is less coherent, perhaps even less rigorous and unified in its construction, than any of its predecessors. This reaction may be due in part to a further erosion of regular pulse (indeed, the bar line has now often disappeared entirely), and in part to a diminished reliance on the unifying and organizing potential of strict contrapuntal procedures such as canon. Still another factor is the existence and exploitation of a vastly expanded palette of colour; because the characteristic pitches and figures are given so many subtly different shades of meaning through colouristic changes, their successive appearances are perceived not as recurrences which unify, but rather as metamorphoses which diversify.

However, perhaps the most significant factor which contributes to a perceived lack of rigour is the infiltration of aspects of aleatoric technique into the "composed" parts of the piece. In Quartet no. 3 Pentland included four aleatory zones, whose essential feature was the presentation of a set of significant pitches for each instrument, with explicit instructions to play them first in a particular order, and then to reorder them freely. It is this aspect of her aleatoric technique

16 Pentland's preoccupation with a vertical axis of symmetry should come as no surprise, given her virtual obsession with double inverted canon in the third string quartet.

17 Obviously, in order to have an equal number of pitches above and below a given axis tone, the total number of pitches involved must be odd, not even. 
which she has now actually written in to her non-aleatoric sections in this fourth quartet.

The section which begins at $\mathrm{m} .42$ is a good example of her new procedures, since it shows a gradual change from an initial strict unfolding of the row, through a slight rearrangement of its normal ordering, to a virtual abdication of any allegiance to the row (see example 14).

Having established the normal ordering of her material at the opening of the section (m. 43), Pentland then creates a complex, layered texture of derived material in a manner which is strongly suggestive of group improvisation. The first violin part at mm. 47-50 randomly extracts the significant pitches of its earlier jagged line for more lyrical statement. Meanwhile, the second violin and viola explore new relationships among pitches which had been previously stated by reallocating and reordering them, and arranging them, ostinato-fashion, in mutually interlocking groups. The cello provides a third layer of activity, with a reordered version of the violin and viola parts from $\mathrm{m} .41$ to the first note of m. 43. This cello material of $\mathrm{mm}$. 47-50 is divided and restated by the first violin: $\mathrm{mm}$. 47-48 reappear in $\mathrm{m}$. 54 at $\mathrm{t}=4$, while $\mathrm{mm}$. 49-50 reappear in $\mathrm{m}$. 56 , also at $\mathrm{t}=4$. Furthermore, the cello line of $\mathrm{mm}$. 49-53 has been summarized in yet another ordering in its closing gesture of $\mathrm{m}$. 54. This extraordinarily complicated section, taken as a whole, shows clearly how Pentland has transplanted the essence of her aleatory zones to a fully composed section in this quartet. The initial ordering of material has disintegrated into a seemingly fortuitous textural mosaic whose essential element is the mutual reordering and sharing of material. In short, Pentland has in this quartet made a serious exploration of the continuum between composed and improvised material.

Just five years after completing her fourth string quartet, Pentland turned her hand again to this medium. The fifth quartet, composed in 1985, consists of a single movement, its two principal sections separated by an aleatory zone. Continuity of the whole is ensured, as always with Pentland, by the pervasiveness of the opening material in various guises throughout the work. What distinguishes this quartet from its predecessors is the nature of that opening material. In all previous quartets Pentland has furnished her listeners with a sequential unfolding of the material at the outset. In this fifth quartet, she has provided an eight-note "chord" (her term), arranged in four dyads, followed by four individual tones (which later appear in variable order) to complete the aggregate. Although one may postulate any number of ordered series as possible sources for this "chord" and four following tones, subsequent use of the material renders any such hypothesis entirely irrelevant. The unordered "chord" becomes, in effect, 

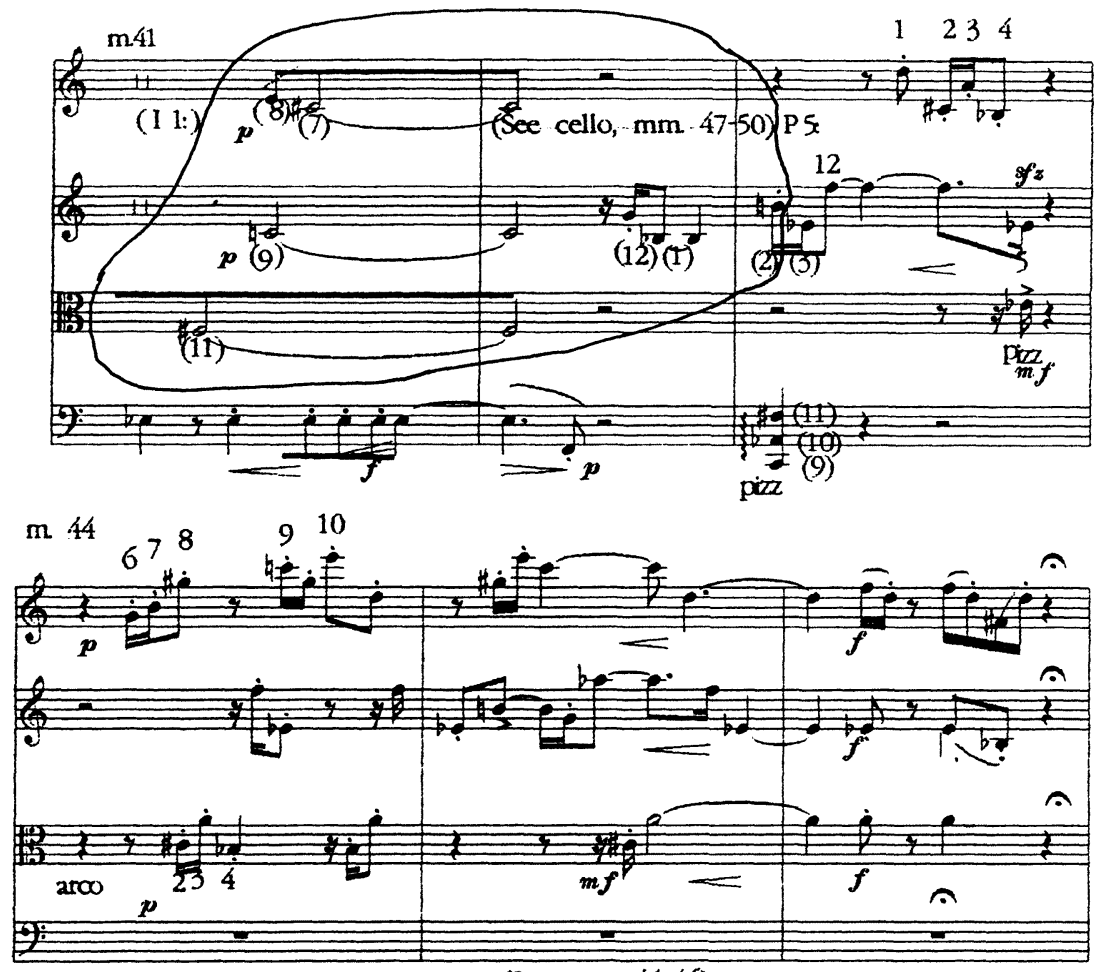

(See mm. 44-46)

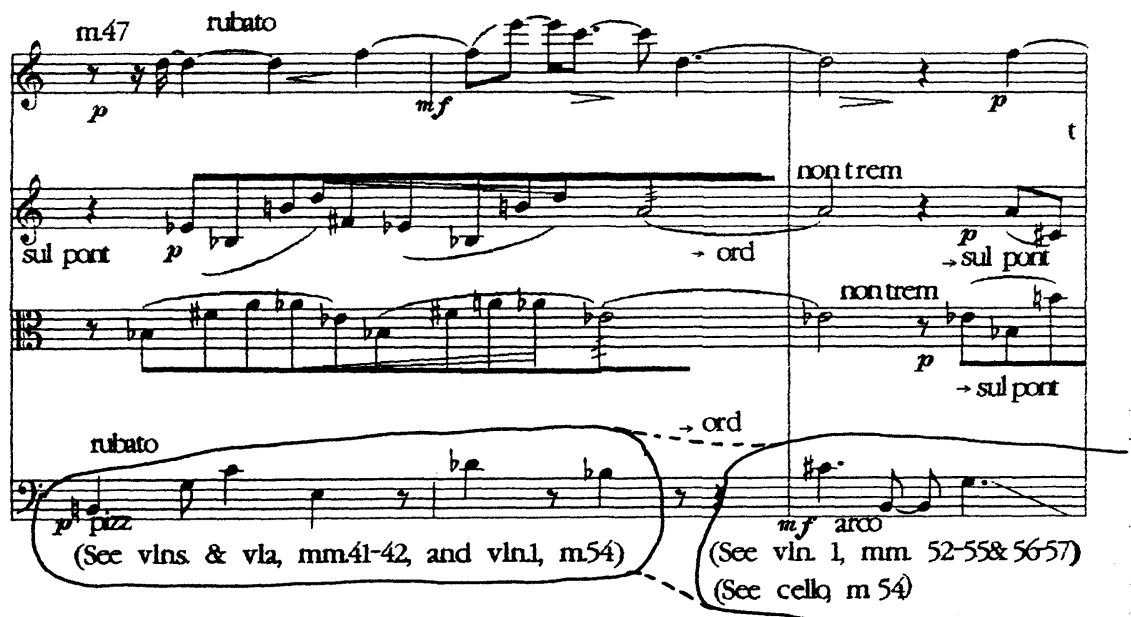

Example 14: String Quartet no. 4, mm. 41-57. 

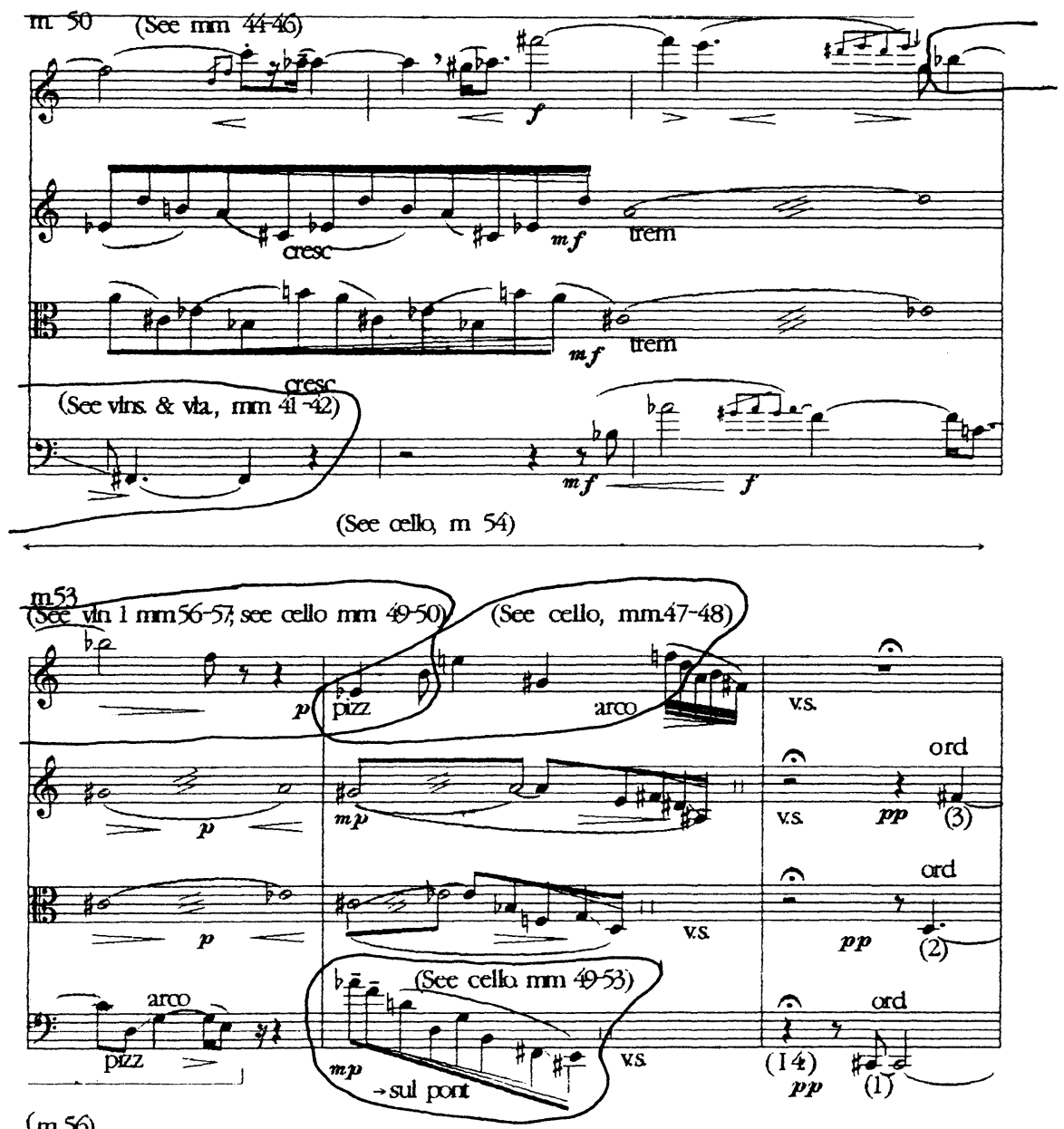

(m 56)

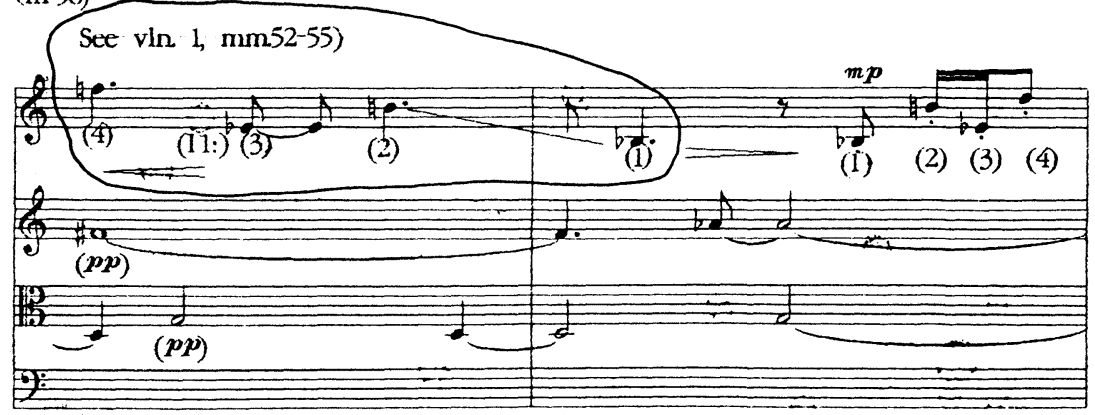
Ho 


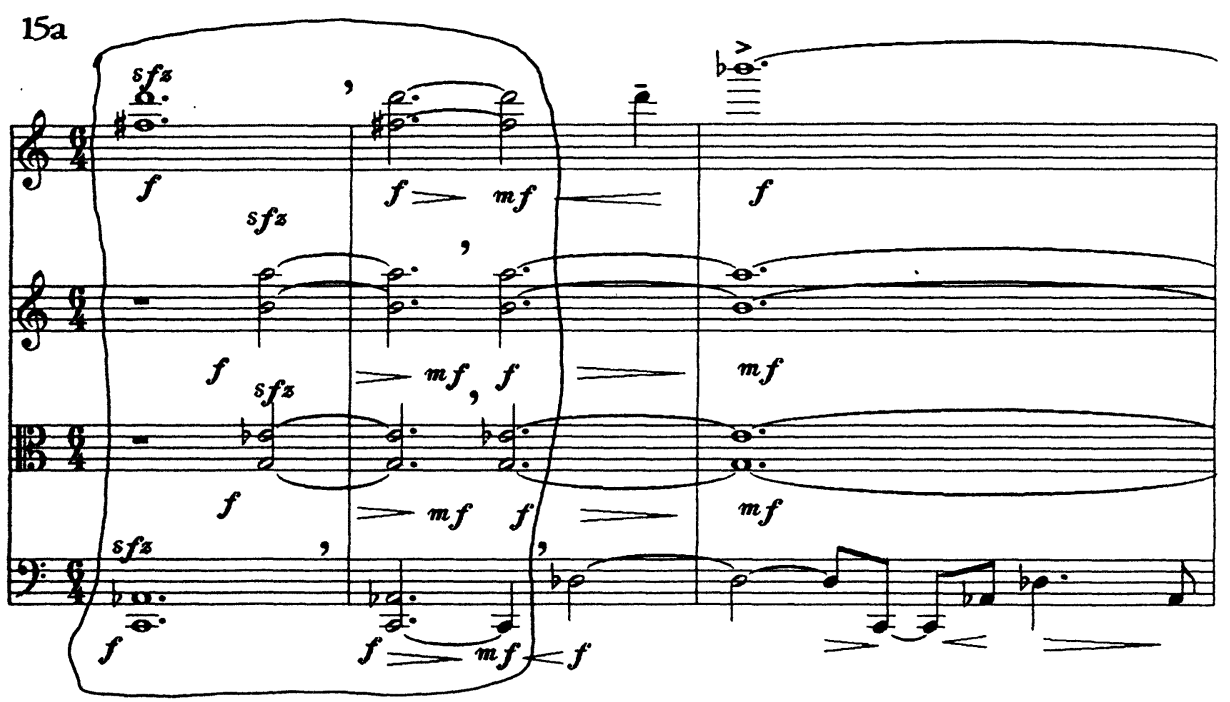

Example 15a: String Quartet no. 5, mm. 1-3.

the real source of subsequent development. Serialism, per se, has ceased to function as a true modus operandi for Pentland in this quartet. Example 15a shows the opening "chord," while examples $15 \mathrm{~b}$ and $15 \mathrm{c}$ show the two different orderings which are subsequently drawn from it. ${ }^{18}$

These "themes"19 (Pentland's term for them) preserve these orderings in subsequent appearances, and are themselves subjected to the usual serial procedures of inversion and transposition. However, the work as a whole can not be described as serial, even allowing for the considerable latitude in ordering which has been a hallmark of Pentland's technique in the past.

Other than the virtual abandonment of serial technique, Pentland's 5th string quartet reveals no startling new departures in her style. There is no further exploration of the continuum between music which is composed and that which

18 Examples 15a, b and c comprise the basic material of the entire quartet. Each recurs in different guises, while retaining its characteristic identity. (For example, the material of example $15 \mathrm{~b}$ is typically embedded within an imitative texture.)

19 In fact, these materials do resemble themes, in the traditional sense, more closely than at any time since the second quartet. 
$15 b$

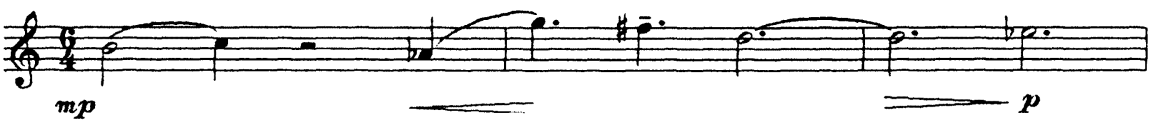

Example 15b: String Quartet no. 5, mm. 15-19, 1st violin.

$15 c$
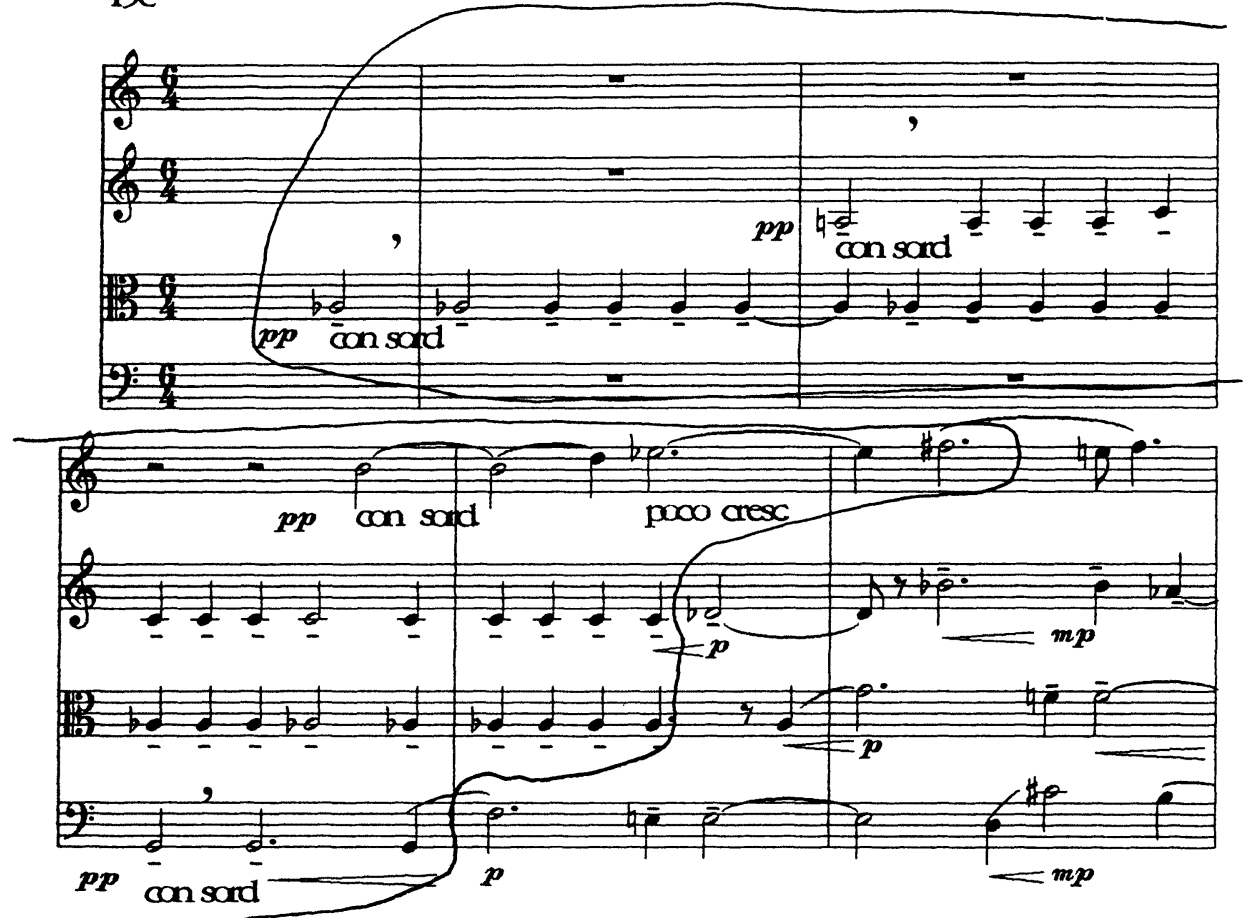

Example 15c: String Quartet no. 5, mm. 30-35.

is improvised, and experiments in the domains of colour and rhythm do not exceed in scope those which were used in quartet no. 4. Indeed, one senses that, like Richard Strauss after Salome and Elektra, Pentland has quite deliberately ceased to probe new territory in favour of a more comfortable conservatism. 
A constant feature in all of the quartets has been the reliance on motives and motivic development as essential compositional elements. What has been subject to change is the means of generating and developing those motives. In Quartet no. 1, motives consist of adjacent tones extracted from lengthy themes, and are developed by the usual means of transposition, inversion, recombination and imitation, as well as by reordering. Motives are frequently elaborated by the insertion of scalar connective tissue, and by the alteration of interval sizes. In Quartet no. 2, motives are created by extracting either adjacent or nonadjacent tones from a 12 -tone row. New material is moulded by reordering tones which were contiguous in their original presentation, though not necessarily contiguous in the row. In addition to the developmental techniques observed in Quartet no. 1, we now see the application of the usual methods of serial manipulation (inversion, retrograde and retrograde inversion) to the motives themselves. The motives of the third quartet result not only from the extraction of tones from a single row, but from a concatenation of two combinatorial rows as well. Because of the new brevity of the motives (often only two notes in length), Pentland turns to colour as a means of developing them. Unusual effects such as variable width vibrato and microtonal inflection now outnumber, though do not supplant, more usual means of enhancing a motive. The new feature which is seen in Quartet no. 4 is the borrowing and sharing of material among motives for simultaneous exploration, a procedure which results in a quasi-aleatoric effect within "composed" portions of the quartet. In Quartet no. 5 , tones of the unordered opening 8-tone "chord" are subsequently ordered in two entirely different ways, to provide material for subsequent development. Ironically, though Quartet nos. 1 and 5 are very different stylistically, they are related in a technical sense through their association (explicit in the case of the 5 th quartet, though not the $1 \mathrm{st}$ ) with an unordered pc set.

The foregoing investigation of specific aspects of Pentland's compositional technique yields convincing evidence that she is a consummate craftsman whose works warrant further detailed exploration. It is to be hoped that this first attempt to uncover the complexities of her craft will stimulate other analysts to undertake further research. Their efforts will certainly be worthwhile, for Pentland is indeed a star in the Canadian musical firmament.

\section{REFERENCES}

EASTMAN, SHEILA and MCGEE, TIMOTHY

1983: Barbara Pentland. Canadian Composers Series 3. Toronto: University of Toronto Press. 


\section{FORTE, ALLEN}

1973: The Structure of Atonal Music. New Haven and London: Yale University Press.

\section{PROCTOR, GEORGE}

1980: Canadian Music of the Twentieth Century. Toronto: University of Toronto Press. 